Voix et Images

\title{
Quand Yves Thériault, alias Pierre Huneau, se déguise en vieux loup de mer...
}

\section{André Vanasse}

Volume 2, numéro 3, avril 1977

Jean Éthier-Blais

URI : https://id.erudit.org/iderudit/200075ar

DOI : https://doi.org/10.7202/200075ar

Aller au sommaire du numéro

Éditeur(s)

Les Presses de l'Université du Québec

\section{ISSN}

0318-9201 (imprimé)

1705-933X (numérique)

Découvrir la revue

\section{Citer cet article}

Vanasse, A. (1977). Quand Yves Thériault, alias Pierre Huneau, se déguise en vieux loup de mer... Voix et Images, 2(3), 437-438.

https://doi.org/10.7202/200075ar d'utilisation que vous pouvez consulter en ligne.

https://apropos.erudit.org/fr/usagers/politique-dutilisation/ 


\section{Quand Yves Thériault, alias Pierre Huneau, se déguise en vieux loup de mer...}

Agoak a quelque peu déçu l'an passé. Oeuvres de chair n'a pas laissé de traces cette année. Mais Moi, Pierre Huneau éclate comme une bombe inattendue. Telle est la trajectoire d'Yves Thériault. On a, à satiété, parlé du bon et du moins bon chez ce grand romancier. Imprévisible, voyageant du nord au sud, d'est en ouest, il a parlé de tout: des Italiens, des Juifs, des Indiens, des Scandinaves, des Espagnols, des Esquimaux, des Québécois et ... des autres.

Qu'Yves Thériault avec Pierre Huneau nous fasse la narration d'un vieux Gaspésien n'a rien d'étonnant. Encore qu'il aurait pu arrêter son choix sur un Texan ou un Bolivien. Ce qui surprend par contre, dans cette courte narration, c'est le merveilleux travail de stylisticien qu'a accompli Yves Thériault. Après une vingtaine de pages de lecture, je n'ai pu m'empêcher de me faire la réflexion suivante: comment ce magicien a-t-il fait pour écrire un texte aussi réussi? A écouter Pierre Huneau je me suis mis à croire qu'Yves Thériault avait, ce qui n'est pas le cas, tout simplement enregistré le récit d'un vieux marin.

Or le vieux loup de mer s'appelle indubitablement Yves Thériault lequel n'a sans doute pas plus voyagé sur une barque de pêcheur que vous et moi. Le voyage, il l'a accompli dans les dictionnaires et les récits marins. II est allé chercher là où il le fallait non seulement le vocabulaire mais aussi le ton juste qui fait de Pierre Humeau un personnage d'une telle vérité que sa signature toute raidie et gauche à la fin de la narration apparaît si vraisemblable qu'on voudrait sauter dans son auto pour aller faire un brin de jasette avec celui qui, devenu gardien de phare sur la basse Côte Nord, nous promet la suite de son histoire:

En dire assez, mais pas en dire trop. Un vieux bavasseux, ça énarfe le monde. J'ai été parlant - sans l'être - toute ma vie, m'a dire comme on dit. Restons-en là. Plus tard un peu, si ça vous plaisait que je continusse, revenez me voir, j'parlerai de ma vie d'ensuite, sus la basse Côte-Nord. (p. 135)

Pour bien décrire Pierre Huneau, il faudrait citer tout le volume. Dire, par exemple, «Mais avoir su eyousque c'est que ça pouvait mener... " ou “En par cas, je m'ai engagé à narrer jusqu'au boutte... " (p. 117) n'est pas à la portée de n'importe qui. Évidemment ce ne sont que deux exemples. 
Je pourrais en citer dix, vingt, trente. Dans cette perspective, je n'ai d'autre choix que de reproduire les premières lignes du récit:

J'ai mis un mois, j'penserais, après que Geneviève ma femme fut défunte, à vornusser de maison en maison, du plain jusqu'au village et à l'entrepôt de poisson, morose et écrianché du coeur et de l'áme. J'ai parfilé ma vie tout ce temps-là, de l'enfance au temps d'homme, du temps d'homme à mon esseulement d'aujourd'hui. Même pour le p'tit âge, j'ai trouvé plus de fils noirs que de fils roses. On a été pauvres, on a été gelés, on a été harassés; j'ai dû rire et jouer, enfánt, mais j'arrive pas à m'en souvenir drette comme j'voudrais. (p. 9)

C'est par ce parler que Pierre Huneau s'impose, un parler à la fois archaïque et extrêmement complexe, un parler qui m'émerveille et m'égare. Pierre Huneau sent le poisson et l'air salin. Face à lui je me suis senti tout à fait ignare. II m'a mené à sa guise dans sá barque de pêcheur.

Du reste, à l'écouter parler, j'ai acquis la certitude qu'il avait aussi mené Yves Thériault par le bout du nez. Car ce qui est fascinant dans ce livre c'est que Pierre Huneau ne correspond en rien au personnage-type du romancier. Ici aucune violence. Une vie calme au contraire, une fidélité à toute épreuve, une sérénité inégalée dans l'amour profond pour Geneviève sa moitié, une sexualité lente et calme comme la mer:

J'avais pas eu tort de crère que le bécotage et ce qui s'ensuit, avec Geneviève ça serait plein d'allure. J'avais cru deviner qu'elle m'aimait gros, comme moi semblablement, mais on s'a pas vraiment lâchés des semaines durant, et la cesse est pas venue aussi tôt que j'avais entendu dire. Y'a fallu du temps, des enfants, des soucis et ben d'aut'choses encore pour que ça se gavagne à plein. Au commencement, les choses allaient doux, allaient tendre. Mon souvenir est de ce tempslà, surtout. (p. 31)

La violence ne viendra donc ni de Pierre Huneau, ni de la nature mais bien de la fatalité. II suffira de quelques bâtons de dynamite oubliés par mégarde dans le sous-sol de la maison pour que celle-ci éclate en mille morceaux entraînant la mort non seulement de la famille mais aussi de la parenté qui avait été convoquée à la seule fête qu'ait jamais donnée la famille Huneau. Seul Pierre Huneau aura été épargné et c'est "écrianché du cœur et de l'âme qu'il ira s'échouer sur la basse Côte Nord pour y refaire "sa vie d'ensuite». Cette deuxième vie nous la connaîtrons peut-être. En attendant cet heureux événement, lisez donc la première. Cela en vaut la peine. 